\title{
In-vitro study of hierarchical structures: anodic oxidation and alkaline treatments onto highly rough titanium cold gas spray coatings for biomedical applications
}

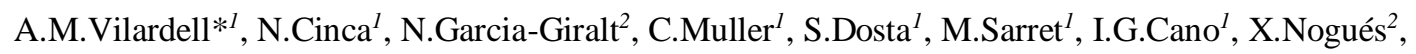
J.M.Guilemany ${ }^{l}$

${ }^{1}$ Centre de Projecció Tèrmica (CPT). Dpt. Material Science and Physical Chemistry. Universitat de Barcelona Martí i Franquès 1, 08028 Barcelona, Spain.

${ }^{2}$ IMIM (Institut Hospital del Mar d'Investigacions Mèdiques), CIBERFES, ISCIII, Doctor Aiguader 88, 08003 Barcelona, Spain

*Corresponding author: A.M.Vilardell [amvilardell.research@gmail.com]

\begin{abstract}
Hierarchical structures were obtained applying two different nanotexturing surface treatments onto highly rough commercial pure titanium coatings by cold spray: (i) anodic oxidation and (ii) alkaline treatment. An extended surface characterization in terms of topography, composition, and wettability has been performed to understand how those parameters affect to cell response. Primary human osteoblasts extracted from knee were seeded onto the as-sprayed titanium surface before and after the nanotexturing treatments. Cell viability was tested by using MTS and LIVE/DEAD assays, as well as osteoblasts differentiation by alkaline phosphatase (ALP) quantification at 3 and 10 days of cell culture. The combination of micro-/nano-roughness results in a significantly increase of cell proliferation, as well cell differentiation after 10 days of cell culture in comparison with the non-treated coatings.
\end{abstract}

Keywords: in-vitro; anodic oxidation; alkaline treatment; titanium coating; cold gas spray

\section{INTRODUCTION}

Cell-surface interactions play a crucial role for biomaterial application in orthopaedics. The progressive application of surface treatment strategies in medicine has gained increasing interest to improve the cytocompatibility and osteointegration of orthopaedic implants [1]. Specially, different methods are purposed to generate nanostructured surfaces such as: laser treatment [2], SLA [3], anodic oxidation [4] and alkaline treatment [5] among others. One of the reasons for that is the analogy to the inorganic phase grain size, being of $10-50 \mathrm{~nm}$ as average in immature bone and of $20-50 \mathrm{~nm}$ in mature bone [6]. In vitro studies have already shown that surface features at the nanometer scale stimulate and control several molecular and cellular events on the tissue/implant interface, which can be observed by differences in cell morphology, orientation and proliferation [7]. In addition, nanometer sized topographies may be useful for reducing bacteria adhesion. Although still a controversy, some research reported that a nanotubes 
(NTs) diameter of $80 \mathrm{~nm}$ decreases bacteria adhesion [8], as well as the intrinsic antibacterial properties of titanium oxide. On the other hand, porous and rough surfaces at the micrometer scale offer solution for various problem including aseptic loosening, infections, periprosthetic fractures, and instability. In addition, some studies have shown that implants with micro-nano-textured surfaces possess stronger interfacial bonding strengths [9].

The present paper examines the in vitro performance of two oxidizing treatments to promote nanotexturization on titanium coatings so that a hierarchical structure is formed. One of those treatments is anodizing while the other is alkaline treatment. The anodic oxidation process is currently used to modify Commercial Pure Titanium (CP-Ti) surfaces for biomedical applications, such as in dental implants. The controlled formation of an oxide layer through anodic oxidation treatment enables the formation of an optimum oxide morphology containing highly ordered pore arrays tubular shapes. The formation of $\mathrm{TiO}_{2}$ Nanotubes (NTs) represents a unique combination of shape and functionality where, in the ideal case, materials' properties can be directly influenced by the 1D-nanoscale nature of the geometry [10]. The obtaining of $\mathrm{TiO}_{2}$ NTs surface improves biocompatibility and bioactivity; moreover, it acts as barrier against the corrosion of the titanium, thus improving its corrosion resistance. Previous results found out the improved of bone ingrowth and implant integration, and in addition, a decrease of fibrous tissue was achieved [11]. The alkaline treatment has already been studied during these last decades onto smooth [12] and microrough surfaces (e.g. Ti sandblasted or acid etched substrates [13] and coatings $[14,15])$ and a lot of studies were performed at different process parameters such as: immersion in $\mathrm{NaOH}$ at different times and temperatures $[12,16,17,18,19]$. The obtaining of sodium titanate hydrogel on titanium as a result of an alkaline treatment has become much more popular than pure titanium in dental and orthopaedic applications owing to its higher corrosion resistance and higher bioactivity since it induces apatite formation in Simulated Body Fluids (SBF) [16], thus enhancing promoting ossointegration [20].

The previous two surface treatments have not been much explored on common vacuum plasma sprayed titanium (VPS-Ti) coatings, which is the well-known commercial deposition process to produce titanium coatings onto joint prosthesis. To the authors knowledge, Xie et al. [21] found higher cell adhesion quantity (about 30\% more) on the hierarchical structure than that on the as-sprayed VPS coatings. On the other hand, in vivo results showed that alkaline treatment significantly improved and accelerated the early ingrowth of bone and osseointegration, showing higher shear strength than VPS-Ti as-sprayed implants at 1 month [20]. In addition, the use of low vacuum requirements imposes high industrial costs so that the viability of using the Cold Gas Spray (CGS) [22] technique is also here investigated. CGS is a solid-state deposition method, in which solid particles (5-50 $\mu \mathrm{m}$ in diameter) are accelerated in a supersonic gas jet to velocities up to $500-1000 \mathrm{~m} / \mathrm{s}$. During the impact with the substrate, particles undergo plastic deformation and adhere to the substrate. CGS is suitable technique for the deposition of oxygen-sensitive materials, as could be titanium, or for temperature-sensitive materials like nanostructured and amorphous powders. Highly rough CGS CP-Ti coatings have been successful according to ASTM standard specification for joint prosthesis [23]. 
Therefore, the novelty that is presented in this work is twofold: (i) the achievement of hierarchical structures by the combination of the CGS process with an oxidation treatment i.e. anodic oxidation and alkaline surface treatment and, (ii) the in vitro comparison of the two combined systems. Concerning the anodizing treatment, this has been just reported in the literature in one patent for an aluminium CGS coating but for a completely different application [24]. The evaluation of titanium oxidized structures is examined in terms of surface morphology, topography, structure and cell performance.

\section{MATERIALS AND EXPERIMENTAL METHOD}

\subsection{Sample preparation}

An irregular coarse commercial pure Ti (CP-Ti) powder was used to obtain highly rough surfaces by CGS. The feedstock particles possess a particle size distribution $-150+90 \mu \mathrm{m}$ and were sprayed onto a previously \#240 SiC grinded Ti6Al4V alloy substrate of $2 \mathrm{~mm}$ thickness and $7 \mathrm{~mm} \times 7 \mathrm{~mm}$ dimension size for in-vitro tests. The spraying conditions for the CP-Ti coating were previously optimized [25]. The CGT KINETICS® 4000 (Cold Gas Technology, Ampfing, Germany) was used in order to produce the rough titanium coatings; such equipment operates with a maximum gas pressure of 40 bars and gas temperature of $800{ }^{\circ} \mathrm{C}$.

Two different nanotexturing treatments previous optimized were performed onto rough titanium coatings: (i) anodic oxidation and (ii) alkaline treatment. The anodization step was performed on titanium coatings using a DELTA ELEKTRONIKA SM 400-AR-4 power supply with a two-electrode configuration, controlled by LabVIEW. An AA304 stainless steel foil was used as auxiliary electrode. An ethylene glycol bath with $5 \mathrm{wt} \% \mathrm{H}_{2} \mathrm{O}$ and $0.5 \mathrm{wt} \% \mathrm{NH}_{4} \mathrm{~F}$ was used. $30 \mathrm{~V}$ for $45 \mathrm{~min}$ were applied in the anodization process. A heat treatment in argon atmosphere at $450{ }^{\circ} \mathrm{C}$ for $1 \mathrm{~h}$ was performed in order to obtain the anatase phase [26]. On the other hand, an alkaline treatment was applied to titanium coatings in order to improve surface biocompatibility [16,27]; such treatment consists in an immersion of 3 days in $5 \mathrm{M} \mathrm{NaOH}$ at $80{ }^{\circ} \mathrm{C}$. Finally, samples were washed with distilled water and dried in an oven at $40{ }^{\circ} \mathrm{C}$. In order to obtain a crystalline phase, a heat treatment in argon atmosphere was performed at $600{ }^{\circ} \mathrm{C}$ during $1 \mathrm{~h} \mathrm{[16]}$.

\subsection{Coating characterization}

Field Emission Scanning Electron Microscopy (FESEM) JEOL JSM 7100F was used to analyse the top surface morphologies of nanotextured coatings. The structure of the coating was analysed by a X'Pert PRO MPD diffractometer (PANalytical). The roughness of the coatings was measured by confocal microscopy (Leica DCM3D) and the results are presented with the 2D profile Ra and Rz values, as well as its division in roughness and waviness according to ISO 4287, at a magnification of 10x and a stitching of 2x2. Surface at nano scale level was measured by Atomic Force Microscope (AFM) Multimode8 with Nanoscope V electronic controller (Bruker) and a SNL probe K: 0.35N/m (Bruker). A home-made water contact angle goniometer with ImageJ software program has been used for the measurement of contact angles, performing static measurements in sessile drop mode. In order to examine microstructure features within the coating, a thin lamella nanotextured layers was obtained by Focused Ion Beam (FIB) lift-out technique. A FEI Strata Dual Beam 235 system was used. Finally, Transmission Electron Microscopy 
(TEM) examinations were carried out using a JEM 2100 microscope, operated at $200 \mathrm{kV}$ (with current density of $80-250 \mathrm{pA} / \mathrm{cm}^{2}$ ).

\subsection{Osteoblast culture}

Human osteoblastic cells (hOB) have been obtained from knee trabecular bone after prosthesis replacement following the protocol described by Nacher et al. [28]. The study has been approved by the of Parc de Salut Mar Ethics Committee. Briefly, trabecular bone was dissected in small pieces that were washed in phosphate-buffered solution (PBS) and placed into a $15 \mathrm{~cm}$ diameter Petri dish containing 15 ml Dulbecco's modified Eagle's medium (DMEM) supplemented with 10\% FBS, penicillin (100 UI/ml), streptomycin (100 UI/mL), ascorbic acid (100 mg/ml) (Invitrogen) and fungisone (0.4\%) (Gibco). Explants were incubated at $37^{\circ} \mathrm{C}$ in a humidified atmosphere of $5 \% \mathrm{CO}_{2}$, changing the medium once a week until cell confluence. Finally, cells were changed into new $75 \mathrm{~cm}^{2}$ flasks until the suitable number has been reached. A maximum of a third subculture has been used in the experiments. For materials testing, samples were overnight sterilized in ethanol $70^{\circ}$, washed in PBS and placed on a 48-well polystyrene culture plate (Nunc A/S). Each material was seeded with 100.000 cells and cultured with DMEM supplemented with 10\% FBS and ascorbic acid; for mineralization assays $\beta$-glycerophosphate (5 $\mathrm{mM}$ ) was also added. Samples were tested at 3 and 10 days of culture. Tests were carried out three times in order to ensure reproducibility. Results were normalized by titanium sample well within each experiment

\subsection{Osteoblast viability and proliferation}

Cell proliferation has been tested using the MTS assay CellTiter 96® AQueous One Solution Cell Proliferation assay (Promega) according to manufacturer's protocol. $50 \mu \mathrm{l}$ of MTS were added in each sample cultured with $250 \mu \mathrm{l}$ of supplemented medium, incubating for 3 hours and then recording the absorbance at $490 \mathrm{~nm}$.

LIVE/DEAD Viability/Cytotoxicity assay Kit for Mammalian Cells (Invitrogen) was performed in order to characterize cell viability, attachment and distribution. It discriminates live from dead cells by simultaneously staining with green-fluorescent calcein-AM (live cells) and red-fluorescent ethidium homodimer-1 (dead cells). Live/Dead assay was performed by adding $300 \mu 1$ of a solution at $4 \mu \mathrm{M}$ EthD1 and $2 \mu \mathrm{M}$ of calcein AM in Phosphate-buffered saline (PBS), per sample and incubated for 30-45 min at room temperature. Then, surfaces have been observed with a Confocal TCS SP5 Upright from Leica Microsystems and the images were processed with Fiji software.

\subsection{Osteoblast differentiation}

Osteoblastic cell differentiation levels were evaluated through Alkaline Phosphatase (ALP) activity, using the Abcam's Alkaline Phosphatase Assay Kit. This assay uses p-nitrophenyl phosphate (pNPP) as a phosphatase substrate which turns yellow when dephosphorylated (it turns to p-nitrophenol) by ALP. The resulting absorbance was measured using a scanning multi-well spectrophotometer, at $405 \mathrm{~nm}$. 


\section{RESULTS}

\subsection{Surface characterization}

\subsubsection{Surface morphology}

Figure 1 shows FESEM micrographs of CGS CP-Ti coating as prepared and after surface treatments. The use of coarse titanium particles as feedstock facilitated the obtaining of highly rough surfaces and internal porosity (Fig. 1a). The first particles that arrive to the substrate are more deformed because of the tamping effect of further impinging particles; the final outer layer actually results in a top surface with less plastic deformation and high roughness. The use of irregular particles may have also some influence at the submicron topography level because of the small asperities of the as-produced particle topography (Fig. 1b). Figures $1 \mathrm{c}$ and $1 \mathrm{~d}$ show the surface morphology of the nanotextured surfaces after the anodic oxidation and the alkaline treatment respectively. After the anodic oxidation, a $\mathrm{TiO}_{2} \mathrm{NTs}$ layer was formed onto the rough titanium coating, with a pore diameter between 50-100 nm (Fig. 1c), meanwhile alkaline treatment leads to a nanoscale featured surface (Fig. 1d). To remark the different topography observed in the FESEM images, figure 2 shows the 2D and 3D top surface nanotopography micrographs of the CGS CP-Ti coating after the two treatments.

\subsubsection{Surface topography}

Table 1 shows the surface microtopography parameters of the surfaces. The topography profiles are shown as well as its subdivision into microroughness and waviness profiles. The measurements obtained from nanotextured surfaces onto CGS CP-Ti coating did not have significant differences in comparison with the as-sprayed CGS CP-Ti coating. A slight decrease in profile values was observed in both nanotextured surfaces, but still maintains a high roughness profile. Even so, the surface microroughness was well preserved as well as surface waviness.

\subsubsection{Coating composition and structure}

Figure 3 the XRD of nanotextured treatments onto the CGS CP-Ti coatings. The thermal treatment (1h at $450^{\circ} \mathrm{C}$ ) after the anodic oxidation was performed to obtain crystalline $\mathrm{TiO}_{2}$ anatase oxide layer. Crystalline anatase phase has a positive effect on cell behaviour [29]. It is demonstrated that $\mathrm{TiO}_{2} \mathrm{NTs}$ obtained on the CGS-Ti coating are stable up to $580^{\circ} \mathrm{C}$ [30]; after that, the formation of rutile leaded to eventually protrusions emerging from the metal at $550-580{ }^{\circ} \mathrm{C}$ and were considered to be the principal cause of $\mathrm{TiO}_{2}$ NTs collapse [31]. On the other hand, the alkaline treatment hardly shows the presence of sodium titanate layer. Commonly, samples immersed in alkaline solutions with a concentration $>5 \mathrm{M}$ start showing sodium titanate peaks of low intensity between 25-35 and 47-49 in $2 \theta$ on XRD pattern $[5,15]$.

The FESEM (Fig. 1c), AFM (Fig. 2c,d) and XRD (Fig. 3) allow the characterization of the structure and morphology of the $\mathrm{TiO}_{2}$ hierarchical structure obtained by anodic oxidation. However, in order to further comprehend the complex structure of the layer formed upon such alkaline treatment, TEM analysis will be presented. 
For a proper study of the nature of the nanotextured surface, a thin lamella was prepared by FIB lift-out technique to analyse its microstructure. TEM micrographs revealed four different regions within the surface (Fig. 4a). Each region was clearly distinguished from each other due to the grain size. Figure 4b shows the SAED patterns of the regions A and B from figure 4a. The region A belongs to the CGS CP-Ti coating, where each coarse grain presents a monocrystalline SAED pattern. The region B consists in a layer located between the regions $A$ and $C$, and its structure is composed by small grains $(\sim 50-100 \mathrm{~nm})$; the polycrystalline nanostructure of region $\mathrm{B}$ was identified as a $\mathrm{TiO}_{2}$ anatase coming from the alkaline treatment. Figure $4 \mathrm{c}$ shows regions $\mathrm{C}$ and $\mathrm{D}$ from figure $4 \mathrm{a}$. The region $\mathrm{C}$ consists in a polycrystalline structure composed by nanograins $<25 \mathrm{~nm}$. The spots of its SAED pattern have been identified as and $\mathrm{TiO}_{2}$ anatase, although it was perceived the presence of a structure similar to apatite (probably some calcium impurities from the $\mathrm{NaOH}$ feedstock). In addition, region $\mathrm{D}$ belongs to the porous sodium titanate layer with a thickness of $\sim 500 \mathrm{~nm}$. The spots have been mostly identified as $\mathrm{Na}_{2} \mathrm{TiO}_{3}$. The porous sodium titanate layer was composed by a polycrystalline structure with small grains of a size of $\sim 100 \mathrm{~nm}$. This micrograph confirms the polycrystalline structure of the sodium titanate layer, as lot of reports identified it as a "microcrystalline or amorphous" layer [15,17]. Figure $4 \mathrm{~d}$ shows a high-resolution TEM micrograph of region $\mathrm{D}$, in which the $\mathrm{Na}_{2} \mathrm{TiO}_{3}$ nanocrystals with a rectangular morphology and approximate size of $80 \times 20 \mathrm{~nm}$ could be observed.

\subsubsection{Surface wettability}

CGS CP-Ti coatings show a hydrophilic behaviour with a contact angle of $26 \pm 10^{\circ}$. On the other hand, both nanotextured treatments turned out to make the surface superhydrophilic with a contact angle value of $0^{\circ}$. It is already reported that hydrophilicity could be induced by surface topography [32], but also by surface composition, as could be the formation of the anatase phase [33]

\subsection{In-vitro characterization}

\subsubsection{Cell viability and proliferation}

Figure 5 shows the image results of Live/Dead test of CGS CP-Ti coatings at 3 and 10 days of cell culture. In all cases there was an increase of cell proliferation but especially on the surfaces in which nanotexturing treatments were performed. The anodic oxidation treated sample was the one that showed higher cell proliferation (Fig. 5b,e), followed by the alkaline treated (Fig. 5c,f) and the non-treated CGS CP-Ti samples (Fig. 5a,d). The MTS assay corroborated the results observed in the Live/Dead assay (Fig. 6). At 3 days of cell culture, a higher number of cells were observed for CGS CP-Ti coating. However, cell proliferation increased faster onto samples in which was applied a nanotexturing treatment up to 10 days of cell culture, showing significant differences.

\subsubsection{Cell differentiation}

Figure 7 shows the ALP results of CGS CP-Ti coatings before and after the nanotexturing treatments at 3 and 10 days of cell culture. Small differences among surfaces were observed at 3 days of cell culture, with a higher value of ALP from nanotexturing treated samples. However, at 10 days of cell culture, there 
was an increase of ALP activity from both nanotextured treated samples, especially from alkaline treated sample, in comparison with as-sprayed CGS CP-Ti coating showing significant differences.

\section{DISCUSSION}

The micro/nano surface modification technologies for titanium may involve changes in surface topography as well as in composition and structure, thus modifying the wettability performance and the final biological properties [16,34,35].

The resulting crystalline titanium oxide phase after thermal treatment on both nanotexturing treatments has a strong influence on cell behaviour. Crystalline $\mathrm{TiO}_{2}$ anatase surfaces enhance cell response in comparison with the as-sprayed CGS CP-Ti coatings. Cell proliferation and differentiation values significantly increase after 10 days of cell culture on both nanotextured samples. Previous in vitro studies on titanium oxide surfaces [36] noted that at the early stage, eg. 2-12h of cell incubation, there was no difference in the data among the $\mathrm{Ti}$, amorphous anodized and crystalline anodized surfaces. However, the number of attached cells on the crystalline $\mathrm{TiO}_{2} \mathrm{NTs}$ markedly increased as the culture time was extended to 24 and 48h [36]. Crystalline anatase provides hydrophilicity and is more favourable for such purposes than the rutile phase [37]. From another hand, alkaline treated samples on titanium surfaces after a subsequent heat treatment lead to a most rapid formation of apatite due to surface crystallinity; sodium titanate and titanium oxide might be hydrolyzed in SBF and negatively charged Ti-OH groups might be formed on the surfaces $[15,16,38]$. Unfortunately, no in-vitro studies were found comparing both nanotexturing treatments until now.

Apart from the surface composition, the increase of surface area by nanotexturing treatments leads to an increase of hydrophilicity. In the case of anodization, also the dimensions of the nanotubes can play a role $[39,40]$. Surface wettability is basically influenced by surface composition and surface free area. The increase of surface area by the nanotexuring treatments, increases the number of atoms at the surface, which increases surface defect density and results in larger proportions of surface electron delocalization [41,42]. This higher surface energy, which enhances hydrophilicity, has been associated with increased protein adsorption and, consequently, osteoblast adhesion [43], which is a necessary prerequisite for subsequent functions, such as deposition of calcium-containing mineral. Xie et al. [21] reported that both, high surface area and surface energy made the $\mathrm{TiO}_{2} \mathrm{NT}$ layer is beneficial for protein adsorption and therefore the early responses of the human marrow stem cells onto VPS-Ti porous coating.

The combination of different surface topographies and an accurate thermal treatment significantly promotes initial cell adhesion, proliferation and differentiation [44]. The obtained micro/nano-textured surfaces is a suitable topography modification that retains the mechanical interlocking ability of the microtopography thereby bonding well for osseointegration, and the good cell response of the nanotopography [45]. Between both nanotextured samples, the $\mathrm{TiO}_{2} \mathrm{NTs}$ deposits obtained by the anodic oxidation shows a more ordered and structured surface in comparison with the one obtained by the alkaline treatment. $\mathrm{TiO}_{2}$ NTs array facilitates cell filopodia anchoring, thus enhancing cell proliferation. Well-developed cell filopodia directly entered nanometer-sized pores for the initial attachment of the osteoblastic cells. These nanometre structures may also give the cells positive guidance by means of the 
selective attachment of osteoblasts to the implant surface [46]. Nano/micro hierarchical hybrid structures of $\mathrm{TiO}_{2}$ NTs onto VPS-Ti coatings enhanced osseointegration, being a good candidate for hard tissue replacements, especially for load bearing implant [21]. On the other hand, the ALP activity of CGS CP-Ti coating with nanotextured treatments was increased significantly up to 10 days in comparison with the assprayed CGS CP-Ti coating. F-actin fibers play a crucial role in modulating cell modulus, elasticity and maintenance of cell shape. Observations that nanoscale topographies induce increased expression of actin stress fibers relative to flat surfaces may thus explain the mechanism by which surface nanoscale roughness affects cellular surface attachment [47]. The combination of micro- and nano- roughness has a significant influence on ALP activity [48, 49].

Differences of cell proliferation and differentiation up to 10 days of cell culture between both nanotextured samples could be understood in terms of topography and surface energy or composition. The application of hierarchical structures increases cell contact with the structure, providing more appropriate spaces for cell proliferation but also differentiation [48]. Feng et al. [49] studied the adhesion of osteoblasts on titanium and different surface oxide titanium films through the calculation of surface energy values, considering a contribution of dispersion components $\left(\gamma^{\mathrm{d}}\right)$ and polar components $\left(\gamma^{\mathrm{p}}\right)$. They indicate that dispersion components $\left(\gamma^{\mathrm{d}}\right)$ in surface energies were similar, whereas the polar components $\left(\gamma^{\mathrm{p}}\right)$ presented were significantly different. $\left(\gamma^{\mathrm{p}}\right)$ increased in order of: pure titanium <oxide titanium surface (produced by thermal treatment $600{ }^{\circ} \mathrm{C}$ during $30 \mathrm{~min}$ in air) <oxide titanium surface (produced by thermal treatment $600{ }^{\circ} \mathrm{C}$ during $30 \mathrm{~min}$ in oxygen), the same as the order of the number of adhered cells and ALP activity. These results indicated that $\left(\gamma^{\mathrm{p}}\right)$ influenced the behaviour of the hOB on Ti surfaces more strongly compared to $\left(\gamma^{\mathrm{d}}\right)$, which was probably attributed to the fact that $\mathrm{TiO}_{2}$ and $(\mathrm{OH}) \mathrm{s}$ groups on the surfaces and the compositions in cells and the culture medium are polar. Higher $\left(\gamma^{\mathrm{p}}\right)$ leaded to higher interaction energy and the products would be more stable leading good cell attachment and spreading. However, further studies should be considered to determine more specifically the effect of the different surface parameters.

\section{Conclusions}

Titanium oxide hierarchical structures were successfully obtained by applying two different nanotexturing surface treatments onto highly rough as-sprayed CGS CP-Ti coatings. The combination of hierarchical micro-/nano-roughness significantly leads to better cell response in comparison with the as-sprayed CGS $\mathrm{CP}-\mathrm{Ti}$ coating. A higher cell proliferation and cell differentiation values were obtained up to 10 days of cell culture.

The obtaining of a homogeneous nanostructure of $\mathrm{TiO}_{2} \mathrm{NTs}$ after the anodic oxidation process leads to the highest cell proliferation values. The organized porous nanostructure may facilitate cell attachment thus favouring cell proliferation. On the other hand, best cell differentiation values were obtained on the surface nanostructure after alkaline treatment due to the composition and the structure of the system. 


\section{Acknowledgments}

The authors also want to thank the Spanish MINECO (AEI) for financial support through project MAT2013-46755-R and the Generalitat de Catalunya for the project 2014 SGR 1558, and University of Barcelona for the award of a scholarship that has helped the development of this research. This work was supported by the Red Temática de Investigación Cooperativa en Envejecimiento y Fragilidad (RETICEF; RD12/0043/0022) and FEDER funds.

\section{REFERENCES}

[1] M. Jäger, C. Zilkens, K. Zanger, R. Krauspe, Significance of Nano- and Microtopography for CellSurface Interactions in Orthopaedic Implants. J. Biomed. Biotechnol. 2007 (2007) 1-19.

[2] R. Zhang, Y. Wan, X. Ai, B. Men, T. Wang, Z. Liu, D. Zhang, Fabrication of micro/nano-textured titanium alloy implant surface and its influence on hydroxyapatite coatings. J. Wuhan Univ. Technol. Mater. Sci. Ed. 31 (2016) 440-445.

[3] G. Orsini, B. Assenza, A. Scarano, et al, Surface analysis of machined versus sandblasted and acidetched titanium implants. Int J. Oral. Maxillofac. Implants. 15(2000)779-784.

[4] M. Kulkarni, A. Mazare, Schmuki, Iglič A, (2014)Biomaterial surface modification of titanium and titanium alloys for medical applications In book: Nanomedicine, Chapter: Biomaterial Surface Modification Of Titanium and Titanium Alloys for Medical Applications, Publisher: One Central Press, Editors: Alexander Seifalian, Achala de Mel, Deepak M. Kalaskar, pp.111-136

[5] M. Wei, H.M. Kim, T. Kokubo, JH. Evans, Optimising the bioactivity of alkaline-treated titanium alloy. Mater. Sci. Eng. C. 20 (2002)125-134.

[6] M. Jayaraman, U. Meyer, M. Bühner, U.Joos, HP. Wiesmann, Influence of titanium surfaces on attachment of osteoblast-like cells in vitro. Biomater. 25 (2004) 625-631.

[7] S. Minagar, J. Wang, CC. Berndt, EP. Ivanova, C. Wen, Cell response of anodized nanotubes on titanium and titanium alloys: Cell Response of Anodized titania Nanotubes. J. Biomed. Mater. Res. A 101A(2013)2726-2739.

[8] B. Ercan, E. Taylor, E. Alpaslan, TJ. Webster, Diameter of titanium nanotubes influences antibacterial efficacy. Nanotechnology. 22(2011)295102.

[9] N. Sykaras, AM. Iacopino, VA. Marker, RG. Triplett, RD. Woody, Implant materials, designs, and surface topographies: their effect on osseointegration. A literature review. Int. J. Oral Maxillofac. Implants. 15(2000)675-690.

[10] A. Ghicov, P. Schmuki, Self-ordering electrochemistry: a review on growth and functionality of TiO2 nanotubes and other self-aligned MOx structures. Chem Comm 20(2009)2791-2808. 
[11] DJ Hall, RM. Urban, R. Pourzal, TM Turner, AK. Skipor, JJ. Jacobs, Nanoscale Surface modification by anodic oxidation increased bone ingrowth and reduced fibrous tissue in the porous coating of titanium-alloy femoral hip arthroplasty implants. J. Biome. Mater. Res. 105B (2017) 283-290.

[12] T. Kokubo, F. Miyaji, H-M. Kim, T. Nakamura, Spontaneous Formation of Bonelike Apatite Layer on Chemically Treated Titanium Metals. J. Am. Ceram. Soc. 79(1996)1127-1129.

[13] S. Tugulu, K. Löwe, D. Scharnweber, F. Schlottig, Preparation of superhydrophilic microrough titanium implant surfaces by alkali treatment. J. Mater. Sci. Mater. Med. 21(2010)2751-2763.

[14] SW. Ha, KL. Eckert, E. Wintermantel, H. Gruner, M.Guecheva, H.Vonmont, NaOH treatment of vacuum-plasma-sprayed titanium on carbon fibre-reinforced poly(etheretherketone). J. Mater. Sci. Mater. Med. 8(1997)881-886.

[15] F. Liang, L. Zhou, K. Wang, Apatite formation on porous titanium by alkali and heat-treatment. Surf. Coat. Technol. 165(2003)133-139.

[16] M. Wei, H.M. Kim, T. Kokubo, JH. Evans, Optimising the bioactivity of alkaline-treated titanium alloy. Mater. Sci. Eng. C. 20 (2002)125-134.

[17] H-M. Kim, F. Miyaji, T. Kokubo, T. Nakamura, Apatite-Forming Ability of Alkali-Treated Ti Metal in Body Environment. J. Ceram. Soc. Jpn. 105(1997)111-116.

[18] H. Melero, N. Garcia-Giralt, J. Fernández, A. Díez-Pérez, JM. Guilemany, Comparison of in vitro behaviour of as-sprayed, alkaline-treated and collagen-treated bioceramic coatings obtained by high velocity oxy-fuel spray. Appl. Surf. Sci. 307(2014)246-254.

[19] W. Xue, X. Liu, X. Zheng, C. Ding, In vivo evaluation of plasma-sprayed titanium coating after alkali modification. Biomater. 26(2005)3029-3037.

[20] W. Xue, X. Liu, X. Zheng, C. Ding, In vivo evaluation of plasma-sprayed titanium coating after alkali modification, Biomaterials. 26 (2005) 3029-3037.

[21] Y. Xie, H. Ao, S. Xin, X. Zheng and C. Ding, Enhanced cellular responses to titanium coating with hierarchical hybrid structure. Mater. Sci. Eng. C. 38(2014)272-277.

[22] AM. Vilardell, N. Cinca, A. Concustell, S. Dosta, IG. Cano, JM. Guilemany, Cold spray as an emerging technology for biocompatible and antibacterial coatings: state of art. J. Mater. Sci. 50(2015)4441-4462.

[23] AM. Vilardell, Thesis dissertation. Functionalized coatings by Cold Spray for joint prosthesis. University of Barcelona (2016) 
[24] W. Bogue, BW. Bunting, RJ. Derosa, GM. Lomasney, J.Parkos. Patent. Hard anodize of cold spray aluminum layer (EP 2204473 A2). July 7, 2010.

[25] JM. Guilemany, N. Cinca, S. Dosta, IG. Cano, Intelectual Property: Feasibility of cold gas spraying to produce high roughness high porous titanium coatings for metallic prosthesis, Ref Number 1870 - . Universitat de Barcelona. Legal Deposit: 17/10/2014, Spain, 2014

[26] C. Santiveri, (2016). Master dissertation (University of Barcelona). Anodizing of titanium coatings with different roughnesses, 1-67.

[27] S. Nishiguchi, H. Kato, M. Neo, M. Oka, HM. Kim, T. Kokubo, T. Nakamura, Alkali- and heattreated porous titanium for orthopedic implants. J. Biomed. Mater. Res. 54(2001)198-208.

[28] M. Nàcher, J. Aubia, S. Serrano, M.L. Mariñoso, J. Hernández, J. Bosch, A. Díez, J.M. Puig, J. Lloveras, Effect of cyclosporine A on normal human osteoblasts in vitro, Bone Miner. 26 (1994) 231243.

[29]S. Minagar, J. Wang, CC. Berndt, EP. Ivanova, C. Wen, Cell response of anodized nanotubes on titanium and titanium alloys: Cell Response of Anodized titania Nanotubes. J. Biomed. Mater. Res. A $101 \mathrm{~A}(2013) 2726-2739$.

[30] D. Regonini, A. Jaroenworaluck, R. Stevens, CR. Bowen, Effect of heat treatment on the properties and structure of $\mathrm{TiO}_{2}$ nanotubes: phase composition and chemical composition. Surf. Interface. Anal. 42(2010)139-144.

[31] D. Regonini, CR. Bowen, A. Jaroenworaluck, R. Stevens, A review of growth mechanism, structure and crystallinity of anodized $\mathrm{TiO}_{2}$ nanotubes. Mat. Sci. Eng. R. 74(2013)377-406.

[32] K-Y. Law, H. Zhao, Surface Wetting. Springer International Publishing, 2016

[33] KS. Brammer, S. Oh, CJ. Cobb, LM. Bjursten, H. van der Heyde, S. Jin, Improved bone-forming functionality on diameter-controlled $\mathrm{TiO}_{2}$ nanotube surface. Acta Biomater. 5(2009)3215-3223.

[34] F. Rupp, L. Scheideler, N. Olshanska, M. de Wild, M. Wieland, J. Geis-Gerstrofer, Enhancing surface free energy and hydrophilicity through chemical modification of microstructured titanium implant surfaces. J Biomed Mater Res A 76A(2006)323-334.

[35] SV. Gnedenkov, SL. Sinebryukhov, VS. Egorkin, DV. Mashtalyar, DA. Alpysbaeva, LB. Boinovich, Wetting and electrochemical properties of hydrophobic and superhydrophobic coatings on titanium. Colloids Surf A: Physicochem Eng Asp 383(2011)61-66.

[36] S. Oh, C. Daraio, L-H. Chen, TR. Pisanic, RR. Fiñones, S. Jin, Significantly accelerated osteoblast cell growth on aligned $\mathrm{TiO}_{2}$ nanotubes. J. Biomed. Mater. Res. 78A(2006) 97-103. 
[37] KM. Kummer, EN. Taylor, NG. Durmas, KM. Tarquinio, B. Ercan, and TJ. Webster, Effects of different sterilization techniques and varying anodized $\mathrm{TiO}_{2}$ nanotube dimensions on bacteria growth. J. Biomed Mater Res. App. Biomater. 101B(2013)677-688.

[38] H. Takadama, H.M. Kim, F. Miyaji, T. Kokubo, T. Nakamura, in: R.Z. LeGeros, J.P. LeGeros (Eds.), Bioceramics, vol. 11, World Scientific, New York, 1998, pp. 663-666.

[39] S. Oh, K. S. Brammer, Y. S. J. Li et al., "Stem cell fate dictated solely by altered nanotube dimension," Proceedings of the National Academy of Sciences of the United States of America, vol. 106, no. 7, pp. 2130-2135, 2009

[40] Z. Xu, Y. Lai, D. Wu, W. Huang, S. Huang. L. Zhou, J. Chen, Increased Mesenchymal Stem Cell Response and Decreased Staphylococcus aureus Adhesion on Titania Nnotubes without Pharmaceuticals. Biomed Res Int. 2015(2015)9

[41] RW. Siegel, Creating nanophase materials. Sci. Am. 275(1996)42-47.

[42] KJ. Klabunde, J. Stark, O. Koper, C. Mohs, DG. Park, S. Decker, Y. Jiang, I. Lagadic, D. Zhang, Nanocrystals as Stoichiometric Reagents with Unique Surface Chemistry. J. Phys. Chem. 100(1996)12142-12153.

[43] J. Davies, The Importance and Measurement of Surface Charge Species in Cell Behaviour Interface, in B.D. Ratner (Eds.), Surface Characterization of Biomaterials, Elsevier, New York, 1988, pp. 219-234.

[44] T. Wang, Y. Wan, Z. Liu, Fabrication of hierarchical micro/nanotopography on bio-titanium alloy surface for cytocompatibility improvement. J. Mater. Sci. 51(2016)9551-9561.

[45] L. Zhao, S. Mei, PK. Chu, Y. Zhang, Z. Wu, The influence of hierarchical hybrid micro/nanotextured titanium surface with titania nanotubes on osteoblast functions. Biomater. 31(2010)5072-5082.

[46] L. Le Guéhennec, A. Soueidan, P. Layrolle, Y. Amouriq, Surface treatments of titanium dental implants for rapid osseointegration. Dental Mater. 23(2007)844-854.

[47] JC. Hansen, J. Yul Lim, L-C. Xu, CA. Siedlecki, DT. Mauger, HJ. Donahue, Effect of surface nanoscale topography on elastic modulus of individual osteoblastic cells as determined by atomic force microscopy. J. Biomech. 40(2007)2865-2871.

[48] H. Jeon, CG Jr Simon, G. Kim, A mini-review: Cell response to microscale, nanoscale, and hierarchical patterning of surface structure alloys, J. Biomed. Mater. Res. 102A (2014) 1580-1594.

[49] B. Feng, J. Weng, BC. Yang, SX. Qu, XD. Zhang, Characterization of surface oxide films on titanium and adhesion of osteoblast. Biomater. 24(2013)4663-4670. 